\title{
Funciones y características del condicionamiento extrafílmico del espectador en el cine de terror
}

\author{
Javier Sanz Aznar | javier.sanz@ub.edu \\ Universitat de Barcelona \\ Juan José Caballero Molina | juanjo.caballero@ub.edu \\ Universitat de Barcelona
}

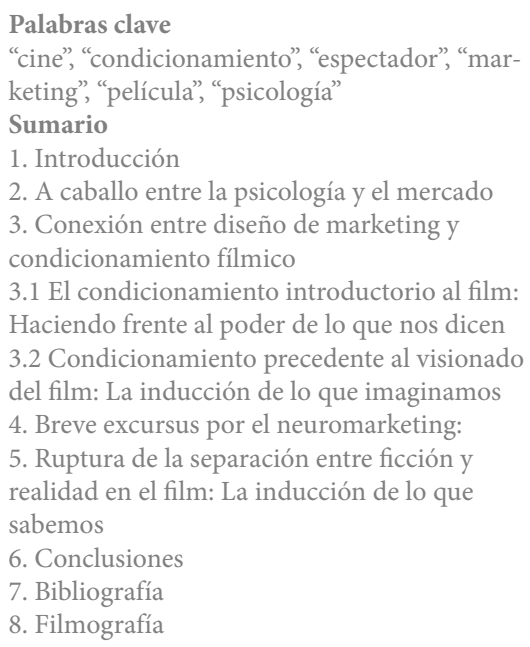

\section{Resumen}

La experiencia cinematográfica se desarrolla siempre bajo un estado de ánimo o un conjunto de circunstancias que delimitan y determinan la recepción de la obra, así como la naturaleza de los procesos cognitivos desencadenados por la misma, o el propio valor comunicativo que puede llegar a ser extraído por parte del público. En definitiva, esta experiencia se formula o construye sobre un determinado pacto de consumo, sobre el que inciden acciones o estrategias planificadas con el objeto de condicionar de la manera más eficaz posible el impacto emocional y comercial de la obra. El cine de terror nos brinda un escenario privilegiado para la evaluación y el análisis de algunas de estas medidas que han acreditado su efectividad en el curso de los años, a la luz de las valiosas aportaciones realizadas en el ámbito de la psicología experimental. En el presente artículo analizamos diferentes estrategias que son aplicadas sobre el espectador antes de que acceda a la propia sala de proyección y lo condicionan en su experiencia cinematográfica. A través de estas estrategias se logra sensibilizar al espectador y hacerlo más vulnerable ante el film de terror que va a experimentar.

\section{Cómo citar este texto:}

Javier Sanz Aznar, Juan José Caballero Molina (2021): Funciones y características del condicionamiento extrafílmico del espectador en el cine de terror, en Miguel Hernández Communication Journal, Vol. 12 (1), pp. 21 a 40. Universidad Miguel Hernández, UMH (Elche-Alicante). DOI: https://doi.org/10.21134/mhcj.v12i.939 


\section{Functions and characteristics of the spectator's extra-filmic conditioning in horror films}

Javier Sanz Aznar |javier.sanz@ub.edu

Universitat de Barcelona

Juan José Caballero Molina |juanjo.caballero@ub.edu

Universitat de Barcelona

Keywords

"cinema", "conditioning", "film", "marketing",

"psychology", "spectator"

Summary

1. Introducción

2. A caballo entre la psicología y el mercado

3. Conexión entre diseño de marketing y condi-

cionamiento fílmico

3.1 El condicionamiento introductorio al film:

Haciendo frente al poder de lo que nos dicen

3.2 Condicionamiento precedente al visionado del

film: La inducción de lo que imaginamos

4. Breve excursus por el neuromarketing:

5. Ruptura de la separación entre ficción y reali-

dad en el film: La inducción de lo que sabemos

6. Conclusiones

7. Bibliografía

8. Filmografía

\begin{abstract}
The cinematographic experience always happens under an emotional state and it's influenced by contextual circumstances that determine the reception of the film, modifying the degree the cognitive strategies and the communicative value for the spectator. The cinematographic experience is formulated on a certain consumption pact, on which planned strategies affect in order to conditionate the emotional and commercial impact of the work in the most effective way. Horror films provides us with a privileged setting for the evaluation and analysis of some of
\end{abstract} valuable contributions made in the field of experimental psychology. This article aims to analyse different strategies applied to the spectator before they enter to the theatre itself, conditioning them in their cinematographic experience. Through these strategies, it is possible to sensitize the spectator and make them more vulnerable to the horror film that is going to experience.

\section{How to cite this text:}

Javier Sanz Aznar, Juan José Caballero Molina (2021): Funciones y características del condicionamiento extrafílmico del espectador en el cine de terror, en Miguel Hernández Communication Journal, Vol. 12 (1), pp. 21 a 40. Universidad Miguel Hernández, UMH (Elche-Alicante). DOI: https://doi.org/10.21134/mhcj.v12i.939 


\section{Introducción}

El ser humano se desenvuelve en unos aqui y abora, concretos, de los cuáles no puede substraerse. Existen infinidad de circunstancias y contextos que condicionan nuestra respuesta ante una tarea concreta, pudiéndose suscitar ciertas actitudes que pueden ser incluso opuestas a aquellas que se dimanarían del hecho de haber de hacer frente a la misma tarea sin la mediación de estos condicionamientos previos. Incluso mediante sencillas fórmulas de condicionamiento semántico ${ }^{1}$ se llega a verificar el modo en que la incidencia emocional de ciertas palabras sobre el individuo puede variar sustancialmente tras verse sometido éste a una determinada estrategia previa de condicionamiento inducido (Richards y Blanchette, 2004).

La experiencia cinematográfica se desarrolla siempre bajo unas ciertas coordenadas personales y contextuales, así como también unas condiciones psicológicas y sociológicas precisas. Éstas contribuyen a determinar el estado de ánimo o el conjunto de circunstancias bajo los cuáles se produce la recepción de la obra, así como la naturaleza y el tipo de procesos cognitivos desencadenados por la misma, o el propio valor comunicativo que puede llegar a ser extraído por parte del público.

De aquí deriva la formulación de un pacto de consumo que puede remontarse mucho tiempo atrás, y puede estar entretejido con nuestro propio recorrido biográfico; como también puede obedecer a imperativos o estímulos mucho más inmediatos y ser resultado de condicionamientos forzados desde la propia la maquinaria industrial cinematográfica. Entre los últimos, encontramos aquellos asociados con los reclamos orquestados o sobrevenidos durante el desarrollo de las campañas de promoción y lanzamiento de la obra, o que guardan una estrecha relación con las mismas.

Es por estos reclamos y las estrategias desplegadas en torno suyo, por los que, en esta ocasión, nos interesamos. Nuestro objetivo pasa, en primera instancia, por perfilar la naturaleza del diseño de las acciones promocionales, tradicionalmente implementadas con vistas a alcanzar el condicionamiento efectivo de la relación emocional sostenida por el público con la obra enmarcada dentro de una producción genérica concreta, como es aquella propia del cine de terror, programáticamente orientada hacia la consecución de intensas respuestas cognitivas en el público.

Con este objeto, en el texto se procede a correlacionar las diversas estrategias de intervención promocional adoptadas con las bases cognitivas que las presiden, contribuyendo, de este modo, a su pertinente análisis dentro del entorno de una experiencia cinemática, planificada en virtud de desplegar de manera efectiva el condicionamiento negativo, inscrito en el reto que, como veremos, se lanza al público potencialmente receptivo.

${ }^{1} \mathrm{El}$ condicionamiento semántico consiste en la asociación de dos estímulos diferentes, siendo uno de ellos verbal. 


\section{A caballo entre la psicología y el mercado}

Desde el ámbito de la psicología, se han llevado a cabo diversos experimentos en los que se condiciona al sujeto de estudio antes de enfrentarlo ante un material audiovisual que contiene un evento de alta intensidad emocional con valencia negativa, permitiendo regular su reacción ante el mismo. Entre los ejemplos experimentales de condicionamientos de esta naturaleza, hallamos: inducir a una valencia emocional positiva o negativa (Wegerer, et al., 2013; James, et al., 2016), mentalizar al sujeto de que está —o no- preparado para asimilar las imágenes que va a observar (Brown, et al., 2012; Woud, et al., 2013), así como también inducirle la idea de que los sucesos negativos son frecuentes o, por contra, raros (Schartau, Dalgleish y Dunn, 2009). A través de todos estos condicionamientos previos al visionado, se logró incidir sobre la forma en que los sujetos de estudio se enfrentaban al contenido audiovisual, y se constató la posibilidad de aumentar o reducir la afectación experimentada ante los mismos sucesos.

En base a las conclusiones extraídas a partir de los citados experimentos, podemos asegurar que el trabajo desarrollado sobre el condicionamiento al cuál se somete al espectador con antelación a verse sumergido en la experiencia cinemática, va a condicionar la efectividad e intensidad con la que la misma pueda llegar a impactarle. Así, en un film de terror, la inserción de una situación traumática puede ser convenientemente instalada incluso antes de tener acceso al visionado del propio film.

En este punto, se hace interesante revisar aquella vieja historia según la cual los espectadores abandonaron la sala de proyecciones corriendo despavoridos ante la amenazante imagen viva del tren aproximándose en La llegada de un tren a la estación de La Ciotat (L'Arrivée D'un Train En Gare De La Ciotat, Auguste Lumière y Louis Lumière, 1895). A pesar de que la misma ha sido desacreditada como un falso mito (Loiperdinger y Elzer, 2004; Duckett, 2014), que no pertenece sino a la leyenda de la que el naciente medio cinematográfico se recubriría, bajo ella se evidencian dos condicionamientos muy claros que operan sobre el espectador: el primero es la naturaleza de la propia experiencia colectiva, compartida, que supone la proyección pública; en tanto que el segundo, ya nos insinúa la irrupción de una seminal estrategia de marketing, diseñada con el objeto de generar interés por dar a conocer del naciente espectáculo cinematográfico, para estimular su consumo.

Resulta de especial interés el indudable condicionamiento que supone saber que acudes a un evento precedido por la fama de haber suscitado la huida de la sala de proyección. El miedo o la prevención ante lo que llegue a suceder, pueden verse eficazmente contrarrestados por la tentación de hacer frente a un reto: el desafío que comporta el tratar de reaccionar de un modo más valeroso, o quizás razonable, que aquellos espectadores que desistieron de continuar el visionado.

Es, en definitiva, por abordar ese condicionamiento que se inscribe dentro del dominio de lo paratextual, y que obedece a la incidencia ejercida mediante una intervención ajena —en mayor o menor medida - al texto propiamente fílmico, por lo que aquí nos interesamos. 


\section{Conexión entre diseño de marketing y condicionamiento fílmico}

El encuentro entre un texto — cualquier texto— y su receptor «[...] jamás es inaugural. El texto ya ha sido leído, tratado por un conjunto de instituciones interpretativas que van desde la crítica hasta los anuncios publicitarios, pasando por los esquemas de programación. El encuentro con el texto aparece así predefinido por la naturaleza del público con el que el texto es compartido y por las evaluaciones y las caracterizaciones de las que ha sido objeto» (Dayan, 1997: 18).

De ahí nace la dificultad de delimitar el inicio — así como también el término— de la experiencia de consumo. En cierto modo, la película se prevé, antes de estar frente a ella. Y eso es algo que, en buena medida, puede ser programado y diseñado de antemano.

De entre todos los elementos externos a la película que pueden incidir decisivamente en la recepción de la misma, destacan aquellos originados por los equipos de marketing que se fraguan y vertebran orientados a promover el consumo de un film particular, potenciando la experiencia espectatorial asociada, al situarse orgánicamente enmarcados dentro del proyecto comercial del propio film, pero alojado fuera de su universo diegético.

El condicionamiento extrafílmico constituye una tentadora y no poco socorrida estrategia de los departamentos de marketing dentro del cine de terror. Mediante el mismo, se pretende tensionar tanto al público potencialmente interesado como a aquél que ya ha adquirido su localidad, contribuyendo a propagar un estado de opinión y de ánimo capaces de suscitar un cierto clima de alarma o prevención social frente al impacto traumático que - se asegura- genera la obra. Ese, insistimos, constituye un mecanismo de reto dirigido hacia un espectador, a quién se cuestiona sobre su capacidad para gestionar o asimilar correctamente la naturaleza de esa experiencia.

En este punto, nos es dado discriminar entre el condicionamiento que se circunscribe al espacio de la sala durante la fracción de tiempo destinada a la liturgia del desarrollo de la proyección, y aquél otro previo, que se desarrolla con el objeto de suscitar el interés en el target concernido por la estrategia publicitaria, para animarlo a que se decida a enfrentarse con la película.

\subsection{El condicionamiento introductorio al film: Haciendo frente al poder de lo que nos dicen}

Históricamente las estrategias destinadas al condicionamiento del espectador habían contemplado la posibilidad de funcionar a modo de antesala de la historia, incorporando, en ocasiones, la figura de un maestro de ceremonias que presentaba la película, a modo de un anexo filmado que se proyecta justo antes de que diera inicio propiamente el relato. Esta estrategia, tal y como sería adaptada por el cine de terror, se sustanciaba en advertir al espectador el riesgo que entrañaba quedarse a ver la película, recomendando — a modo de intimidatorio twist final- que abandonasen la sala si consideraban no estar preparados, 
tanto física como psicológicamente, para soportar someterse a una experiencia traumática de alta intensidad como aquella.

El origen de esta estrategia de marketing podemos encontrarlo, no obstante, fuera del ámbito del terror, en fechas muy tempranas del desarrollo del medio cinematográfico como espectáculo. Así, Charles Chaplin, en Obligaciones (The Bond, 1918), comete la osadía de aparecer él mismo al final del metraje saludando al público y animándolo a suscribir bonos de guerra, justo tras la conclusión del film.

Por esas fechas, David Wark Griffith haciendo uso de un recurso como el foreword abre con sus propias palabras ese melodrama bélico titulado Corazones del mundo (Hearts of the World, 1918). Mediante el mismo, subraya su voluntad de proponernos uno de aquellos particulares alegatos pacifistas suyos frente al dantesco conflicto de la Gran Guerra.

Pero habría de ser, sin duda, el paso al sonoro el que significase una apuesta decidida por dotar de presencia y voz a la figura del autor en lo que son conocidos como prólogos. 2 . La oportunidad que brindaba la ventaja técnica de la incorporación del sonido, permitía aplicando la categorización establecida por Umberto Eco (2016) — al "autor empírico", presentarse y dirigirse en primera persona, como alguien dotado de rostro e identidad, ante su "espectador empírico", interpelándolo. De este modo, rompiendo la cuarta pared antes de que ese espectador sentado en su butaca haya tenido tiempo de sumergirse en la ilusión, también resulta transitoriamente burlado el "modelado" recíproco que se establece entre ambos agentes comunicativos. Mediante esta argucia, el autor se concede desvelar sus intenciones a su espectador o, simplemente, ponerlo en estado de alerta.

A partir de la incorporación de estos prólogos filmados, se contribuye en cierto modo a la democratización de una liturgia del espectáculo público, donde cualquier espectador, independientemente del precio que deba satisfacer por su localidad, en cualquier sala de cualquier sitio del mundo donde esa obra se exhiba, tendría ocasión de contemplar esa presentación o advertencia inicial, donde el autor se da a conocer y advierte al público de que está a punto de vivir una experiencia de alto contenido traumático.

Este condicionamiento previo al film, dada su eficacia, cundiría en especial dentro del género de terror. El aviso filmado anexado actuaba, así, a modo de cuerpo extraño, alojado dentro del tejido textual de la propia obra, pero con un funcionamiento autónomo — pese a su innegable vinculación— respecto al mismo.

Uno de los casos más emblemáticos de esta estrategia dentro del cine de terror, habría de ser el El doctor Frankenstein de James Whale (Frankenstein, Laemmle y Whale, 1931). En esta obra, el propio director se presenta ante el público para hablarle de la sinrazón prometeica

${ }^{2} \mathrm{~A}$ imagen y semejanza de aquellos comentarios que preludiaban las actuaciones dentro de los locales de vaudeville más sofisticados (Gomery, 1981), con la voluntad manifiesta de diferenciar las actuaciones que en los mismos se exhibían, frente a aquellas otras de los locales de la competencia. 
y del eterno misterio en el que se hallan envueltas la vida y la muerte; permitiéndose deslizar durante su intervención una advertencia para que aquellas personas más sensibles abandonen la sala antes de que la película propiamente dé comienzo.

Quedaba codificado de este modo un ostentoso protocolo de alarma, destinado a cuántas personas asistentes a la proyección, que no se considerasen capaces de enfrentarse a la misma. Y se erigía, así, dentro del espectáculo cinematográfico, una suerte de fórmula de reto macabro, dirigido a cuántos espectadores que se decidiesen a no abandonar la sala, que se hallaba en plena sintonía con aquella otra instaurada ya a finales del siglo XVIII, dentro del dominio del espectáculo efectista y truculento de la fantasmagoría, por parte de linternistas como Paul Philidor o Étienne-Gaspard Robert ${ }^{3}$, más conocido como Robertson (Banda y Moure, 2010).

Los prólogos filmados se diferenciaban claramente del universo diegético desplegado posteriormente durante el metraje restante del film, mostrando normalmente una persona mirando a cámara en un plano medio o primer plano. Estos avisos utilizados en el cine de terror, tenían por objeto, tensionar al público, arrastrándolo a un estado de alarma, mediante un tono serio, así como un registro y tono discursivo imperativos, donde — como hemos comentado- incluso se conminaba al público a abandonar la sala antes de que empezase el film.

Así, sucede por ejemplo en el prólogo de esa obra fundacional del subgénero gore que es Blood Feast (Friedman y Gordon Lewis, 1963). En el mismo, aparece un hombre de mediana edad en primer plano, mirando a cámara sobre un fondo monocromo rojo. De gesto serio, con traje formal y con brillos de sudor destacados por la iluminación, se dirige directamente al espectador, para advertirle ante el posible riesgo de salud que pude suponer ver la película para determinadas personas, a las que invita a abandonar la sala dentro de un plazo establecido en noventa segundos.

Una alternativa en el cine de terror a este prólogo filmado, y que remite también a los recursos desplegados por aquellos otros clásicos a los que hemos pasado revista, consiste asimismo en el texto escrito en forma de credit roll, donde se avisa antes de que se inicie el film del impacto que pueden producir las imágenes en el espectador. Así, por ejemplo en el film 2000 Maniacos (Two Thousand Maniacs!, Friedman y Gordon Lewis, 1964), se incrusta un texto blanco sobre fondo rojo con el típico inicio de «The scenes you are about to see [...]», finalizando con la habitual invitación a abandonar la sala en caso de que el espectador no se considere capacitado para soportar lo que va a venir a continuación.

${ }^{3}$ Éstos, al amparo de las lúgubres localizaciones donde se desarrollaba su actuación, asumían el rol de espiritistas dotados de poderes sobrenaturales, mediante los cuales conseguían establecer contacto con el más allá, para convocar a los espectros y toda suerte de manifestaciones demoniacas ante un público sobrecogido por la siniestra liturgia conducida por el linternista. 


\subsection{Condicionamiento precedente al visionado del film: La inducción de lo que imaginamos}

Un segundo tipo de condicionamiento sobre el espectador nos remite a aquél promovido durante las campañas de marketing. El mismo se vería especialmente popularizado gracias a la filmografía de William Castle, donde resurgirían estrategias abiertamente inspiradas en aquella tradición propia de la barraca de feria. Su fortuna comercial se fiaba a la explotación de efectistas argucias publicitarias, conocidas como gimmicks. Estos mecanismos promocionales eran diseñados y difundidos en el circuito de exhibición durante las semanas previas al estreno del film, con el objeto de reclamar el interés de un público esencialmente teenager, para asistir a la sala de cine y contribuir a transformar la proyección en un ritual regido por una liturgia eminentemente lúdica.

Así sucede, por ejemplo, con el tráiler de Escalofrio (The Tingler, Castle, 1959), dónde Castle en persona, facilitaba instrucciones al público para atreverse a participar de la experiencia, y lograr salir con vida de ella. El público congregado debía sumergirse en la misma, con el objetivo de verse sensorialmente interpelado y constituirse en un elemento activo durante su devenir, transgrediendo o burlando la distancia de seguridad que queda establecida entre aquello que sucede en la pantalla y el público ubicado en la platea.

A esas impactantes estrategias publicitarias y sensoriales que se extienden por aquél cine de explotación americano de los años cincuenta, con un target comercial definido en torno a la población adolescente y juvenil, rinde homenaje Joe Dante en su Matinée (Finnell y Dante, 1993). Las mismas pasarían a constituirse en el paradigma del condicionamiento extrafílmico adoptado por aquél cine de terror moderno que proseguiría su andadura bajo el signo del poderoso influjo ejercido por Alfred Hitchcock, cuando éste se decidiera a rescatar el género de las catacumbas de los circuitos secundarios, gracias a Psicosis (Psycho, 1960). Con ella, el maestro del suspense lejos de repudiar la herencia recibida del cine de explotación, se decantó por asumirla y potenciarla de un modo inteligente y juguetón. Así, se acabaría gestando toda una estrategia publicitaria en la que él mismo se involucraría de manera activa, fundada a modo de piedra angular sobre un atípico tráiler de seis minutos y medio de duración, donde él mismo nos presenta la localización principal en la que tienen lugar los hechos.

Durante este tráiler, Hitchcock acompañado por la basculación constante entre los compases de una pieza de música bufa y los de uno de los temas de la BSO original compuesta por Bernard Hermann, nos presenta la casa y el motel de los Bates, identificándolos como los escenarios donde sucedieron los crímenes. Traza, de este modo, una peculiar crónica negra de los escabrosos acontecimientos allí acaecidos, mediante la que anticipa tanto como insinúa y — sobre todo- calla, respecto a unos sucesos que se preocupa de revestir de un ambiguo velo de autenticidad.

El tráiler se clausura con un texto escrito, de apoyo a la campaña de advertising diseñada para arropar el lanzamiento comercial de la película, donde en tono imperativo se insiste en que la película debe ser vista necesariamente desde el principio, porque nadie puede acceder a la sala una vez haya dado comienzo la proyección. De este modo Hitchcock conseguía trans- 
formar la sala en una suerte de santuario de un secreto espeluznante, y respondía a aquél viejo recurso de invitar a abandonar la sala, mediante el dictado de una regla que impedía acceder a ella o — más aún—insinuaba que no se podría abandonar hasta el final de la proyección.

Años más tarde, otros cineastas que se valieron del cine de terror para lanzar sus carreras a partir de obras artesanales, de bajo presupuesto, como Tobe Hooper (La matanza de Texas, The Texas Chain Saw Massacre, 1974) o Sam Raimi (Posesión infernal, The Evil Dead, 1981), habrían de recurrir, para generar expectativas, a la difusión de aquellas ostentosas y desproporcionadas reacciones cosechadas por esas películas ante sus primeros espectadores. En todos estos casos, la experiencia traumática asociada con la película da comienzo o resulta instalada psíquicamente antes de que el espectador acuda a la proyección del propio film. Y su lanzamiento comercial recurre a un aparato publicitario centrado en proponer al público el visionado de la obra entendido insistentemente como reto.

Uno de los casos más paradigmáticos en ese sentido vino de la mano de otra de las obras influyentes dentro del género de terror contemporáneo, como habría de ser El exorcista de William Friedkin (The Exorcist, Blatty y Friedkin 1973). Esta obra se convirtió en un auténtico must to see, tanto para aquellas personas que eran aficionadas al género como también para quienes no lo eran, por razones imputables a su truculenta aproximación a un dogma de fe, como representa la figura del demonio. Tener la oportunidad de ver cara a cara al demonio, era algo tan seductor e irresistible para todo tipo de gentes, independientemente de que fuesen, como hemos dicho, seguidoras de ese cine o no, o que fuesen personas con convicciones religiosas o completamente agnósticas.

En paralelo a estas estrategias de marketing oficiales, de manera recurrente, se propagan desde los tiempos de Castle hasta Hereditary (Frakes, et al., 2018) rumores interesados, fraudulentamente revestidos del aspecto de noticias, mediante los que se da a conocer que la gente ha sufrido colapsos, crisis histéricas o vómitos al ver la obra en cuestión, hasta el extremo de que hubieron de ser requeridas ambulancias para tratar a algunos espectadores.

Un caso orquestado no solo para extender estos rumores, revistiéndolos de un halo de verosimilitud, sino al mismo tiempo para reforzar este condicionamiento justo antes de que inicie el film, lo hallamos en Bite (Calahan, Giroux y Archibald, 2015). Antes de iniciar la proyección, algunos cines distribuyeron entre el público asistente bolsas de papel para recoger los vómitos, propiciando mediante esta iniciativa — de neto sesgo publicitario- un claro condicionante ante la experiencia cinematográfica a la que estaban a punto de enfrentarse. Así, se alentaba, además, una eficaz campaña word to mouth, mediante la que se avalaba la percutante naturaleza de la experiencia.

De esta forma, los espectadores influenciados por este tipo de estrategias, inician la experiencia cinematográfica condicionados, motivados a enfrentarse a un reto, al mismo tiempo que hipersensibilizados ante la experiencia que están a punto de arrostrar. 


\section{Breve excursus por el neuromarketing:}

Si nos interesamos por abordar el neuromarketing como potencial condicionamiento del espectador cinematográfico, cabe decir que circula mucho ruido por los medios de comunicación pero transcienden pocas conclusiones concretas. Mientras menudean los artículos periodísticos que claman por el control neuronal que el cine puede ser capaz de generar (Randall, 2011; Europa Press, 2014), las únicas publicaciones científicas existentes en torno al neuromarketing se centran en medir la efectividad del tráiler generando interés en el espectador (Christoforou, et al. 2017; Nazarova y Lazizovich, 2019) y la efectividad del product placement que se introduce en los filmes (Jin y Villegas, 2007; Crespo-Pereira, García-Soidán y Martínez-Fernández, 2019). En este aspecto, a pesar de la amenaza de control neuronal sobre el espectador que frívolamente se ha aventado, ninguna estrategia de neuromarketing ha llegado a acercarse al boom consumista del blue jeans de Levi's desencadenado por los films Rebelde sin causa (Rebel Without a Cause, Weisbart y Ray, 1955) o Salvaje (The wild one, Kramer y Benedek, 1953).

Antes de proseguir, se hace necesario comenzar separando el neuromarketing de la neurocinemática, a pesar de que interesadamente existe una tendencia a definir la neurocinemática como rama del neuromarketing (Lacey, 2010; Romero, 2015). Mientras que el neuromarketing se centra en el sujeto como consumidor, la neurocinemática, a través de mediciones biométricas del espectador, trata de profundizar científicamente en el conocimiento de la experiencia cinemática, investigando a nivel cognitivo, por ejemplo, cómo y porqué se produce el corte invisible (Smith, 2012; Heimann, et al., 2016) o el funcionamiento a nivel biológico del efecto Kuleshov (Calbi, et al. 2017).

Centrándonos en el ámbito del terror, debemos recalar en la colaboración establecida entre el productor cinematográfico Peter Katz y la empresa de neuromarketing MindSign. En 2009 aparecieron varios artículos en medios de comunicación informativos, como por ejemplo CNN, Wired o Slate, promocionando esta cooperación, que se anunciaba iba a estar dedicada a descifrar como conseguir potenciar el miedo que siente el espectador cinematográfico ante una película, merced a un sofisticado a la par que riguroso diseño fílmico basado en los procesos neuronales (Silver, 2009).

Hasta el presente, Katz no ha producido ninguna película remarcable y la empresa MidSign ha desaparecido del mapa empresarial. Este caso recuerda a James Vicary, cuando en 1957 aseguró que en un cine de New Jersey había introducido mensajes subliminales en los films, incrementando el consumo de palomitas y Coca-Cola, haciéndose eco medios de comunicación influyentes como The New Yorker o The Nation (Moore, 1982). Años más tarde Vicary reconocería que todo había sido un fraude y nunca había introducido mensaje subliminal alguno (Veltkamp, Custers y Aarts, 2011). Fue el efecto llamada sumado al efecto placebo, los que consiguieron que el público se creyese ciertamente condicionado a incrementar el consumo.

Siendo así que, en la actualidad y en base a los artículos científicos publicados, aludir al neuromarketing asociado al consumo cinematográfico, no parece sino una treta del propio 
marketing tout court, que tiene por objeto lisa y llanamente que el público se sienta biológicamente indefenso ante el film.

\section{Ruptura de la separación entre ficción y realidad en el film: La inducción de lo que sabemos}

Uno de los atributos que han acreditado un mayor nivel de eficacia en términos del condicionamiento que se ejerce sobre el público es aquél recurrente tag-line del "basado en hecho reales".

Pensar que aquello que nos disponemos a ver ha sucedido (por más que sepamos que se trata de una necesaria y deseable adaptación a las exigencias y prerrogativas propias de la ficción), sitúa al espectador en una disposición o nivel de receptividad distinto, que puede alcanzar a tener una traducción comercial concreta.

Esa ha sido una baza jugada a fondo por determinados productores o cineastas, como pone de manifiesto, en los últimos años, el viraje experimentado por la filmografía de Clint Eastwood, donde desde que en 2006 firma el díptico formado por Banderas de nuestros padres (Flags of Our Fathers, Spielberg, Lorenz y Eastwood, 2006a) y Cartas desde Iwo Jima (Letters from Iwo Jima, Spielberg, Lorenz y Eastwood, 2006b), se suceden sin cesar obras que esgrimen esa condición de estar inspiradas sobre acontecimientos o sucesos que han tenido lugar ${ }^{4}$. La memoria colectiva parece demandar obras de todo aquello cuanto no ha quedado registrado, pero de lo que se hace preciso levantar acta.

El cine de terror también ha sabido aprovechar esta asunción de (re)presentar hechos reales de forma más rigurosa y fundada, como en el caso de The girl next door (Miller, van der Houten y Wilson, 2007), o tomándose mayores licencias narrativas como en La matanza de Texas (The Texas Chain Saw Massacre, Hooper, 1974), Las colinas tienen ojos (The Hills Have Eyes, Locke y Craven, 1977) o en todas las películas inspiradas por los Warren 5

Esta afinidad con la realidad puede tener como premisa de partida determinados casos particulares, como los ejemplos anteriormente mencionados, u optar también por formular una narración sintética, inspirada por la combinación de diferentes hechos reales, como sucede en el caso de Tiburón (Jaws, Brown, Zanuck y Spielberg, 1975), basada en una serie de muertes que tuvieron lugar en 1916, en Nueva Jersey ${ }^{6}$, y la historia de cómo Frank Mundus atrapó un tiburón; en Wolf Creek (McLean, 2005), que remitía a los casos de Ivan Milat y Bradley John Murdoch, o en Pesadilla en Elm Street (A Nightmare on Elm Street, Shaye y Craven, 1984), que se inspiraría en tres artículos aparecidos en la década de los 70 en L. $A$.

${ }^{4}$ Como son los films dirigidos posteriormente por Clint Eastwood El intercambio (Changeling, Lorenz, et al., 2008), Invictus (Lorenz, et al., 2009), Sully (Marshall y Eastwood, 2016), 15:17 Tren a Paris (The 15:17 to Paris, Meier, et al., 2018) y Richard Jewell (Davisson, et al., 2019).

${ }^{5}$ Cuyo inicio cinematográfico cabe situar en Terror en Amityville (The Amityville horror, Geisinger, Saland y Rosenberg, 1979).

${ }^{6}$ Entre el 1 y el 12 de julio de 1916 se produjo una ola de ataques de tiburón en la costa de New Jersey, produciendo cuatro muertos y un herido. 
Times sobre refugiados de guerra traumatizados del sur de Asia, que tenían miedo a dormir debido a las terribles pesadillas que sufrían, y que en algunos casos finalizarían trágicamente falleciendo.

Dentro de los films que parten de situaciones reales, destacan los centrados en personajes auténticos como La angustia del miedo (Angst, Reitinger-Laska y Kargl, 1983) o M, el vampiro de Düsseldorf ( $M$, Nebenzal y Lang, 1931), o aquellos otros que derivan en una especie de biopics macabros, como es el caso de Henry: Retrato de un asesino (Henry: Portrait of a Serial Killer, Dedmond, Jones y McNaughton, 1986). Estos films, más que ser fieles a los hechos concretos, se basan en personajes que han existido, para sembrar la perturbadora idea de que "el lobo está dentro del gallinero", y que, de algún modo, tras cualquier desconocido e incluso conocido, puede ocultarse un asesino en serie.

Un experimento (Appel y Male $\square \mathrm{kar}$, 2012) analiza la persuasión que produce en el receptor de la narración el conocimiento paratextual de si una historia es real o ficticia. Para ello propusieron el mismo relato para todos los participantes en el experimento, a los que dividieron en tres grupos de estudio. $\mathrm{Al}$ inicio del experimento indicaron a los sujetos de estudio que el relato era auténtico, ficción o un simple bulo, en función del grupo en el que estuviesen enclavados.

Las conclusiones que se extrajeron de este experimento señalaron que los receptores de la historia que la consideraban ficticia esperaban estar más entretenidos y resultaban abiertos al universo narrativo que se les ofrecía. Sin embargo, a los miembros del grupo al que se les había dicho que la historia era real, la consideraban más útil y fidedigna que la ficticia, es decir, la consideraban constituida por unos hechos que resultaban de mayor relevancia que la percepción reflejada por los individuos de aquel otro grupo que la creían una historia ficticia.

La investigación descrita remite a los investigadores Mar y Oatlay (Oatley, 1999; Mar y Oatley, 2008) quienes sostienen que la información transmitida como ficción está orientada al conocimiento social, mientras que la información transmitida como real está orientada al conocimiento del mundo. Esto marca que al enfrentarnos a una historia real se busque aprender hechos que expliquen el mundo, mientras que al hacerlo a una de ficción lo que se pretende es comprender la experiencia humana a través de los personajes, marcando esta diferenciación un importante condicionamiento previo en el individuo. Y ese cambio de actitud y posicionamiento frente a los hechos narrados, es algo que puede quedar fijado por la información previa facilitada al individuo, donde se categoriza la naturaleza del relato de forma independiente al mismo.

En esta misma línea de condicionamiento, una estrategia efectiva consiste en convencer al público, mediante publicidad encubierta y/o engañosa así como gracias a la activación de determinados recursos técnico-estéticos (cámara en mano, discontinuidad, enfoque defectuoso... en definitiva aquello que podría ser definido como una factura técnica precaria o desaseada), que los sucesos traumáticos contenidos en la obra están basados en hechos reales o que incluso ésta incorpora registros auténticos de los mismos. 
El ejemplo paradigmático de esta estrategia se halla en ese segmento de largo recorrido comercial que se ha popularizado bajo la denominación de found footage, en el que se sitúan ejemplos seminales como Holocausto caníbal (Cannibal Holocaust, Di Nunzio, Palaggi y Deodato, 1980) o Snuff (Bravman, et al., 1975), donde lo que desfila ante nosotros es una serie de aberrantes sucesos, que se nos garantiza discursiva y técnicamente —a través de una puesta en escena premeditadamente tosca o desaliñada - como real. Se ven reforzadas, así, de un modo ostensible las consecuencias negativas de la exposición al evento traumático, al precipitarlo en el ámbito informativo, en lugar de mantenerlo dentro del universo ficcional al cual pertenece.

El caso de Holocausto caníbal alcanzó, en especial, una importante difusión, sirviendo de fuente espuria sobre la cuál basar pretendidos reportajes en diferentes medios como la revista Interviu en España, donde se afirmaba que el material con el que se había confeccionado la película procedía de filmaciones reales de un equipo documental que murió durante el rodaje (Gracia, 1980). Se sabe que para poder llevar a cabo el engaño publicitario de Holocausto caníbal los actores firmaron un contrato comprometiéndose a que ninguno podía aparecer en medios de comunicación ni desmentir su muerte, llegando a emitirse un juicio por asesinato contra el propio director del filme Ruggero Deodato (Cuomo y De Angelis, 2003).

Otro tipo de escándalo más siniestro es aquél que se suscitaría en torno a la serie de películas Guinea Pig, hacia finales de los 80, cuando fueron haladas las cinco primeras entregas de la saga (todas las existentes, con anterioridad a 1990) entre la colección personal del asesino en serie Tsutomu Miyazaki, y se descubrió que fueron utilizadas por el mismo a modo de fuente de inspiración de sus escabrosos crímenes, llegando incluso a recrear en sus asesinatos alguna de las escenas del film (Balmain, 2011). Este caso resulta de especial interés, ya que su narrativa no están basado en hechos reales, sino que por el contrario, son los crímenes reales los que se basan en el contenido ficcional de los films. En occidente, las mismas se dieron a conocer en 1992 cuando Charlie Sheen en una fiesta vio imágenes de Flower of Flesh and Blood (Ginîpiggu 2: Chiniku no hana, Ogura y Hino, 1985) y contactó con el FBI para denunciarla como una película snuff (McRoy, 2008; Balmain, 2011).

En todos estos casos hasta ahora comentados, la película comienza para el espectador antes de que éste empiece a verla. Y el potencial impacto que pueda ejercer sobre éste, su carga traumática, ya ha suscitado con antelación toda suerte de conjeturas y expectativas. La frontera que divide la realidad de la ficción se torna difusa, permitiendo que un material audiovisual destinado al entretenimiento se llegue a confundir con registros documentales auténticos. Se vulnera, así, la seguridad de la que se reviste el espectador de ficción, confiado de que aquello a lo que ha asistido tan sólo existe en el dominio de la pantalla.

\section{Conclusiones}

Cualquier acción comunicativa se halla regida por unas determinadas cláusulas e inscrita dentro de unos determinados límites. Es decir, está regulada. Y esa regulación puede resultar tan sutil y silenciosa, como evidente y ruidosa. 
En el caso de la experiencia cinemática, sobre ella pueden incidir aspectos biográficos del espectador, el conocimiento cinematográfico que éste mismo pueda atesorar o el propio hecho de convertir el visionado en una experiencia colectiva, como también — según hemos visto- otros marcos reguladores, impuestos, que pueden ejercer una incidencia decisiva y directa sobre la experiencia espectatorial, en virtud de unos objetivos comerciales concretos.

Estas intervenciones externas, a las que hemos aludido, acreditan una presencia destacada dentro del cine de terror, con el objeto de transformar su consumo en una experiencia lo más excitante posible. Es decir, algo capaz de transformarse en un verdadero reto, consistente, como hemos visto, en haber de hacer frente a un acontecimiento potencialmente traumático, que desafíe o ponga a prueba la entereza, resiliencia o capacidad de aguante del público.

Este reto cabe la posibilidad de concebirlo y tratarlo indistintamente como un recurso, un medio, o como un objetivo, un fin en sí mismo. Y eso es algo que incide ciertamente, de forma clara, en la manera en que ese evento, con antelación, es programado y deliberadamente construido en términos expresivos, comunicativos.

Pero en cualquier caso, también hemos podido comprobar como la condición inexcusable de todo reto pasa por superar a todos cuantos lo han precedido, y eso es algo que se ha traducido en una escalada imparable de la apelación al impacto que se ejerce sobre el espectador.

En nuestra empresa por averiguar cómo se genera ese estado de alerta o excitación, necesario para que un film se convierta en un reto, hemos tenido la ocasión de abordar aquellas estrategias de intervención externas al mismo, procediendo a contrastarlas en virtud de los resultados obtenidos por experimentos psicológicos existentes, relacionados con éstas. Hemos acreditado, de este modo, las bases científicas que avalan la planificada hipersensibilización requerida del público ante el film, así como el condicionamiento de la perspectiva desde la que ese mismo público va a establecer contacto con la obra.

A lo largo del artículo se ha desvelado la lógica propia del condicionamiento negativo, que preside la estrategia consistente en cuestionar la capacidad del espectador para gestionar adecuadamente el potencial traumático del film, para así colateralmente estimular su voluntad de enfrentarse y superar la prueba que le es propuesta, con el objeto de desacreditar esa vulnerabilidad que le era inicialmente atribuida. Como también, nos hemos remitido a los experimentos de Appel y Malečkar (2012), diseñados para constatar la forma diferente en que se percibe un mismo enunciado, relato o film, una vez éste resulta anclado en la conciencia de la persona receptora, ya sea dentro del dominio de lo real o de lo ficticio.

Con esta contribución se ha pretendido plantear una primera aproximación lo más rigurosa y fundada posible (evitando incurrir en cualquier sesgo crítico o prurito teórico de índole puritana o integrista), sobre el modo en que el espectador se enfrenta o da inicio al desarrollo de su vínculo comunicativo con una obra cinematográfica, perteneciente en este caso a una categoría genérica como es la propia del cine de terror, donde el impacto cognitivo ejercido sobre el público se privilegia estratégicamente tanto dentro como fuera del propio film. 


\section{Bibliografía}

Appel, M. y Malečkar, B. (2012). The Influence of Paratext on Narrative Persuasion: Fact, Fiction, or Fake? Human Communication Research, 38(4), 459-484. doi:10.1111/j.14682958.2012.01432.x

Crespo-Pereira, V., García-Soidán, P. y Martínez-Fernández, V. A. (2019). An approach to the implementation of neuromarketing techniques by European private TV broadcasters. Elprofesional de la información, 28(5). doi:10.3145/epi.2019.sep.04

Balmain, C. (2011). Flesh and Blood: The Guinea Pig Films. Asian Cinema, 22(1), 58-69. doi:10.1386/ac.22.1.58_1

Banda, D. y Moure, J. (2010). Avant le cinéma: l'oeil et l'image. París, Francia: Armand Colin.

Brown, A. D., Joscelyne, A., Dorfman, M. L., Marmar, C. R. y Bryant, R. A. (2012). The impact of perceived self-efficacy on memory for aversive experiences. Memory, 20(4), 374383. doi:10.1080/09658211.2012.667110

Calbi, M., Heimann, K., Barratt, D., Siri, F., Umilta, M. y Gallese, V. (2017). How context influences our perception of emotional faces: a behavioral study on the Kuleshov effect. Frontiers in psychology, 8, 1684. doi:10.3389/fpsyg.2017.01684

Christoforou, C., Papadopoulos, T., Constantinidou, F. y Theodorou, M. (2017). Your brain on the movies: a computational approach for predicting box-office performance from viewer's brain responses to movie trailers. Frontiers in neuroinformatics, 11. doi:10.3389/ fninf.2017.00072

Dayan, D. (1997). Prefacio. Relatar al público. En D. Dayan, En busca del público: recepción, televisión, medios (págs. 13-21). Barcelona, España: Gedisa.

Duckett, V. (2014). Unwinding the film spool: Hugo, Méliès, and our return to early film. Studies in Documentary Film, 8(1), 33-42. doi:10.1080/17503280.2014.903584

Eco, U. (2016). Los limites de la interpretación. Barcelona, España: Penguin Random House.

Europa Press. (2014). ¿Cómo manipulan las películas nuestro cerebro? Europa Press, 18 de septiembre. Recuperado de https://www.europapress.es/cultura/cine-00128/noticia-afectan-peliculas-cerebro-20140904103802.html. Web visitada el 30/9/2020.

Gomery, D. (1981). The Economics of US Film Exhibition Policy and Practice. Ciné-Tracts, 12(4), 36-40.

Gracia, V. (1980). Comidos en su propia trampa. Interviu (235), noviembre, págs. 60-63.

Heimann, K., Uithol, S., Calbi, M., Umiltà, M., Guerra, M. y Gallese, V. (2016). “Cuts in Action": A High-Density EEG Study Investigating the Neural Correlates of Different Editing 


\section{MHCJ Vol. 12 (1) | Año 2021 - Artículo no 1 (168) - Páginas 21 a 40 - mhjournal.org}

Techniques in Film. Cognitive Science, 41(6), 1-34. doi:10.1111/cogs.12439

James, E., Lau-Zhu, A., Clark, I., Visser, R., Hagenaars, M. y Holmes, E. (2016). The trauma film paradigm as an experimental psychopathology model of psychological trauma: Intrusive memories and beyond. Clinical Psychology Review, 47, 106-142. doi:10.1016/j. cpr.2016.04.010

Jin, C. y Villegas, J. (2007). The effect of the placement of the product in film: Consumers' emotional responses to humorous stimuli and prior brand evaluation. Journal of Targeting, Measurement and Analysis for Marketing, 15(4), 244-255. doi:10.1057/palgrave.jt.5750049

Lacey, L. (2010). Movies that make you love them. The Globe and Mail, 03 de abril. Obtenido de https://www.theglobeandmail.com/arts/film/movies-that-make-you-love-them/ article4313328/. Web visitada el 30/9/2020.

Loiperdinger, M. y Elzer, B. (2004). Lumiere's Arrival of the Train: Cinema's Founding Myth. The Moving Image, 4(1), 89-118. doi:0.1353/mov.2004.0014

Mar, R. y Oatley, K. (2008). The function of fiction is the abstraction and simulation of social experience. Perspectives on psychological science, 3(3), 173-192. doi:10.1111/j.17456924.2008.00073.x

McRoy, J. (2008). Guinea Pigs and Entrails: Cultural Transformations and Body Horror in Japanese Torture Film. En J. McRoy, Nightmare Japan: Contemporary Japanese Horror Cinema (págs. 15-47). Amsterdam, Paises Bajos: Brill Rodopi.

Moore, T. (1982). Subliminal advertising: What you see is what you get. Journal of marketing, 46(2), 38-47. doi:10.1177/002224298204600205

Nazarova, R. y Lazizovich, T. (2019). Neuromarketing- a Tool for Influencing Consumer Behavior. International Journal of Innovative Technologies in Economy, 5(25). doi:10.31435/rsglobal_iijite/30092019/6664

Oatley, K. (1999). Why fiction may be twice as true as fact: Fiction as cognitive and emotional simulation. Review of general psychology, 3(2), 101-117. doi:10.1037/1089-2680.3.2.101

Randall, K. (2011). Rise of Neurocinema: How Hollywood Studios Harness Your Brainwaves to Win Oscars. Fast Company, 25 de febrero. Recuperado de https://www.fastcompany.com/1731055/rise-neurocinema-how-hollywood-studios-harness-your-brainwaves-win-oscars. Web visitada el 30/9/2020.

Richards, A. y Blanchette, I. (2004). Independent Manipulation of Emotion in an Emotional Stroop Task Using Classical Conditioning. Emotion, 4(3), 275-281. doi:doi. org/10.1037/1528-3542.4.3.275

Romero, J. (2015). Neurocinema ¿Cómo el Neuromarketing actúa en Hollywood? neuromarketing.la, 27 de noviembre Recuperado de https://neuromarketing.la/2015/11/neuro- 


\section{MHCJ Vol. 12 (1) | Año 2021 - Artículo no 1 (168) - Páginas 21 a 40 - mhjournal.org}

cinema-como-el-neuromarketing-actua-en-hollywood/. Web visitada el 30/9/2020.

Schartau, P., Dalgleish, T. y Dunn, B. (2009). Seeing the bigger picture: training in perspective broadening reduces self-reported affect and psychophysiological response to distressing films and autobiographical memories. Journal of abnormal psychology, 118(1), 15. doi:10.1037/ a0012906

Silver, C. (2009). Neurocinema Aims to Change the Way Movies are Made. Wired, 23 de septiembre. Recuperado de https://www.wired.com/2009/09/neurocinema-aims-tochange-the-way-movies-are-made/. Web visitada el 30/9/2020.

Smith, T. (2012). An attentional theory of cinematic continuity. Projections, 6(1), 1-50. doi:10.3167/proj.2012.060102

Veltkamp, M., Custers, R. y Aarts, H. (2011). Motivating consumer behavior by subliminal conditioning in the absence of basic needs: Striking even while the iron is cold. Journal of Consumer Psychology, 21(1), 49-56. doi:10.1016/j.jcps.2010.09.011

Wegerer, M., Blechert, J., Kerschbaum, H. y Wilhelm, F. (2013). Relationship between fear conditionability and aversive memories: evidence from a novel conditioned-intrusion paradigm. PLoS one, 8(11), e79025. doi:10.1371/journal.pone.0079025

Woud, M., Postma, P., Holmes, E. y Mackintosh, B. (2013). Reducing analogue trauma symptoms by computerized reappraisal training-Considering a cognitive prophylaxis? Journal of Behavior Therapy and Experimental Psychiatry, 44(3), 312-315. doi:10.1016/j.jbtep.2013.01.003

\section{Filmografía}

Blatty, W. P. (productor) Friedkin, W. (director) (1973) The Exorcist [cinta cinematográfica]. EE.UU.: Warner Bros.

Bravman, J., Shackleton, A. (productores), Findlay, M., Fredriksson, H., y Nuchtern, S. (directores). Snuff [cinta cinematográfica]. EE.UU.: August Films y Selected Pictures.

Brown, D., Zanuck, R. D. (productores) y Spielberg, S. (director) (1975). Jaws [cinta cinematográfica]. EE.UU.: Zanuck/Brown Productions.

Calahan, C., Giroux, C. (productores) y Archibald, C. (director) (2015). Bite [cinta cinematográfica]. Canadá: Black Fawn Films y Breakthrough Entertainment.

Castle, W. (productor y director) (1959). The Tingler [cinta cinematográfica]. EE.UU.: Columbia Pictures.

Chaplin, C. (productor y director) (1918). The Bond [cinta cinematográfica]. EE.UU.: Charles Chaplin Productions.

Cuomo, A. (Producción) y De Angelis, M. (Dirección) (2003). In the Jungle: The making of 
Cannibal Holocaust [documental cinematográfico]. Italia: Alan Young Pictures.

D.W. Griffith, D. W. (productor y director) (1918). Hearts of the World [cinta cinematográfica]. EE.UU.: D.W. Griffith Productions.

Davisson, J., DiCaprio, L., Hagy, H., Hill, J., Meier, J., Misher, K., Moore, T. (productores) y Eastwood, C. (productor y director) (2019). Richard Jewell [cinta cinematográfica]. EE.UU: Malpaso Productions, Warner Bros., Appian Way, Misher Films y 75 Year Plan Productions.

Dedmond, L., Jones, S. A. (productores) y McNaughton, J. (productor y director) (1986). Henry: Portrait of a Serial Killer [cinta cinematográfica]. EE.UU.: Maljack Productions.

Di Nunzio, F., Palaggi, F. (productores) y Deodato, R. (director) (1980). Cannibal Holocaust [cinta cinematográfica]. Italia: F.D. Cinematografica.

Finnell, M. (productor) y Dante, J. (director) (1993). Matinée [cinta cinematográfica]. EE.UU.: Universal Pictures.

Frakes, K., Knudsen, L., Patrick, B. (productores) y Aster, A. (director) (2018). Hereditary [cinta cinematográfica]. EE.UU.: PalmStar Entertainment y Windy Hill Pictures.

Friedman, D. F. (productor) y Gordon Lewis, H. (director) (1963). Blood Feast [cinta cinematográfica]. EE.UU.: Friedman-Lewis Productions.

Friedman, D. F. (productor) y Gordon Lewis, H. (director) (1964). Two Thousand Maniacs! [cinta cinematográfica]. EE.UU.: Friedman-Lewis Productions.

Geisinger, E., Saland, R. (productores) y Rosenberg, S. (director) (1979). The Amityville horror [cinta cinematográfica]. EE.UU.: American International Productions y Cinema 77.

Hitchcock, A. (productor y director) (1960). Psycho [cinta cinematográfica]. EE.UU.: Paramount Pictures.

Hooper, T. (productor y director) (1974). The Texas Chain Saw Massacre [cinta cinematográfica]. EE.UU.: Vortex.

Kramer, S. (productor) Benedek, L. (director) (1953). The wild one [cinta cinematográfica]. EE.UU.: Columbia Pictures.

Laemmle, C. (productor) y Whale, J. (director) (1931). Frankenstein [cinta cinematográfica]. EE.UU.: Universal Pictures.

Locke, P. (productor) y Craven, W. (director) (1977). The Hills Have Eyes [cinta cinematográfica]. EE.UU.: Blood Relations Company.

Lorenz, R., Howard, R., Grazer, B (productores) y Eastwood, C. (productor y director) (2008) Changeling [cinta cinematográfica]. EE.UU.: Imagine Entertainment y Malpaso Pro- 
ductions.

Lorenz, R., McCreary, L., Neufeld, M. (productores) y Eastwood, C. (productor y director) (2009). Invictus [cinta cinematográfica]. EE.UU.: Warner Bros., Malpaso Productions y Revelations Entertainment.

Lumière, A. y Lumière, L. (productores y directores) (1896). L'Arrivée d'un train en gare de La Ciotat [cinta cinematográfica]. Francia: Lumière.

Marshall, F. (productor) y Eastwood, C. (productor y director) (2016). Sully [cinta cinematográfica]. EE.UU.: Warner Bros., Village Roadshow , Malpaso Productions, Flashlight Films, The Kennedy/Marshall Company y RatPac-Dune Entertainment.

McLean, G. (productor y director) (2005). Wolf Creek [cinta cinematográfica]. Australia: True Crime Channel.

Meier, J., Moore, T., Rivera, K. (productores) y Eastwood, C. (productor y director) (2018). The 15:17 to Paris [cinta cinematográfica]. EE.UU.: Malpaso Productions y Warner Bros.

Miller, W. M., van der Houten, A. (productores) y Wilson, G. (director) (2007). The girl next door [cinta cinematográfica]. EE.UU.: Modernciné.

Nebenzal, S. (productor) y Lang, F. (director) (1931). $M$ [cinta cinematográfica]. Alemania: Nero-Film AG.

Ogura, S. (productor) y Hino, H. (director) (1985). Ginî piggu 2: Chiniku no hana [cinta cinematográfica]. Japón: Sai Enterprise.

Raimi, S. (productor y director) (1981). The Evil Dead [cinta cinematográfica]. EE.UU.: Renaissance Pictures.

Reitinger-Laska, J. (productor) y Kargl, G. (productor y director) (1983). Angst [cinta cinematográfica]. Austria: Gerald Kargl.

Shaye, R. (productor) y Craven, W. (director) (1984). A Nightmare on Elm Street [cinta cinematográfica]. EE.UU.: New Line Cinema, Media Home Entertainment y Smart Egg Pictures.

Spielberg, S., Lorenz, R. (productores) y Eastwood, C. (productor y director) (2006a). Flags of Our Fathers [cinta cinematográfica]. EE.UU.: DreamWorks SKG, Warner Bros., Malpaso Productions y Amblin Entertainment.

Spielberg, S., Lorenz, R. (productores) y Eastwood, C. (productor y director) (2006b). Letters from Iwo Jima [cinta cinematográfica]. EE.UU.: DreamWorks SKG, Warner Bros., Malpaso Productions y Amblin Entertainment.

Weisbart, D. (productor) y Ray, N. (director) (1955). Rebel Without a Cause [cinta cinematográfica]. EE.UU:: Warner Bros. 
MHCJ Vol. 12 (1) | Año 2021 - Artículo no 1 (168) - Páginas 21 a 40 - mhjournal.org

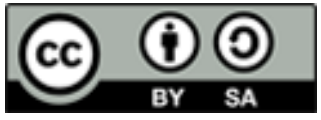

Licencia Creative Commons

Miguel Hernández Communication Journal mhjournal.org

\section{Cómo citar este texto:}

Javier Sanz Aznar, Juan José Caballero Molina (2021): Funciones y características del condicionamiento extrafílmico del espectador en el cine de terror, en Miguel Hernández Communication Journal, Vol. 12 (1), pp. 21 a 40. Universidad Miguel Hernández, UMH (Elche-Alicante). DOI: https://doi.org/10.21134/mhcj.v12i.939 